\title{
Comparison of In-Hospital Outcomes Between Patients With or Without Acute Kidney Injury Developed After Hospitalization Following Acute Coronary Syndrome
}

\author{
MD. SAJJAD SAFI, MSI TIPU CHOWDHURY,TANJIMA PARVIN, KHURSHED AHMED, \\ MD. ASHRAF UDDIN SULTAN, SAJAL KRISHNA BANERJEE \\ Department of Cardiology, Bangabandhu Sheikh Mujib Medical University, Dhaka, Bangladesh.
}

Address of Correspondence: Dr. Md. Sajjad Safi, Resident, Department of Cardiology, Bangabandhu Sheikh Mujib Medical University (BSMMU), Dhaka, Bangladesh. Email: mdsajjadsafi@gmail.com

\begin{abstract}
:
Background: Acute Kidney Injury (AKI), a common complication of acute coronary syndromes (ACS), is associated with higher mortality and longer hospital stays. ACS patients with renal impairment during hospitalization are associated with adverse in-hospital outcomes in the form of heart failure, cardiogenic shock, arrhythmia, dialysis requirement and mortality. Objective: To compare the in-hospital adverse outcomesof patients with ACS with or without AKI.Materials and Methods: This prospective comparative study was conducted in the Department of Cardiology, BSMMU, Dhaka, during the period of August 2017 to July 2018. A total of 70 eligible patients were included in this study of which 35 patients were included in group A (ACS with AKI) and 35 patients were included in group B (ACS without AKI). AKI was diagnosed, on the basis of increased serum creatinine level $0.3 \mathrm{mg} / \mathrm{dL}$ from baseline within 48 hours after hospitalization. They were subjected to electrocardiography, blood test for serum creatinine (on admission, 12 hours, 48 hours and at the time of discharge), lipid profile, 2-D echocardiography along with serum troponin, CK MB and electrolytes. Results: It was observed that mean age was $58.0 \pm 8.5$ years in group $A$ and $55.6 \pm 12.3$ years in group B. Heart failure was more common in group $A$ than in Group B (74.3\% vs $34.2 \%$ p $=0.001$ respectively) and arrhythmia was more common in group $A$ than in Group B (100\% vs $74.2 \%$ respectively). 7(20\%) patients of group $A$ required dialysis. The mean duration of hospital stay was significantly higher in Group A than in the Group $B(9.4 \pm 2.3$ vs 7.2 $\pm 0.6 ; p=0.001)$ days. Multiple logistic regression analysis revealed that heart failure, cardiogenic shock, duration of hospital stay were found to be the independently significant predictors of outcome of the patients with AKI with odds ratio being $5.53(p=0.001), 4.353(p=0.001)$ and $6.92(p=0.001)$ Conclusion: This study shows that, heart failure, cardiogenic shock, arrhythmia, dialysis requirement, were more common in the patients with AKI (group A) than in the patients without AKI (group B). The duration of hospital stays were longer in patients with AKI (group A) than in the patients without AKI (group B). Therefore, an important research target is the identification of high-risk patients with ACS experiencing AKI, thereby appropriate medication and follow-up should be implemented.
\end{abstract}

Keys words: ACS with or without AKI; heart failure; cardiogenic shock; arrhythmia; Hospital stay.

University Heart Journal 2020; 16(1): 3-10

Introduction:

Acute coronary syndrome(ACS) refers to a spectrum of clinical presentations ranging from ST-segment elevation myocardial infarction (STEMI) to nonST-segment elevation myocardial infarction (NSTEMI) to unstable angina (UA). ${ }^{1}$

Acute kidney injury (AKI) is a commonly encountered syndrome associated with various aetiologies and pathophysiological processes leading to decreased kidney function. In addition to retention of waste products, impaired electrolyte homeostasis and altered drug concentrations, AKI induces a generalized inflammatory response that affects distant organs. ${ }^{2}$ It is well stated that ACS may be associated to renal dysfunction and significantly increase mortality, morbidity, and the complexity and cost of care. Syndromes describing the 
interaction between heart and kidney have been defined and classified, but never as a result of a consensus process. Thus, there is limited appreciation of epidemiology and standardized diagnostic criteria. Moreover, prevention and treatment are fragmented, single organ centered and not multidisciplinary in approach. As a result, timing and quality of care may suffer. Most studies have found to be associated with greater short- and long-term all-cause and cardiovascular mortality, prolonged duration of hospitalization, increased readmission rates, accelerated progression to CKD stages and higher healthcare costs. In addition, there seems to be a biological gradient between severity of AKI and risk of death. Even small acute changes in S.Creatinine $(0.3 \mathrm{mg} / \mathrm{dL})$ can modify the risk of death. ${ }^{3}$

The reported incidence of ACS-associated AKI is extremely heterogeneous, ranging from $5 \%$ to $55 \%$, and it varies with the criteria used for diagnosing AKI, the clinical setting and the investigated population. A significant progressive increase in in-hospital mortality was observed in patients with ACS between those without AKI and those with stage 1 , stage 2 and stage 3 AKI ( $1 \%$ vs $9.5 \%$ vs $43 \%$ ). AKI in STEMI complicated by cardiogenic shock, was found to be the strongest independent predictor of in-hospital mortality. ${ }^{4}$ The concept of AKI as a potent risk factor for cardiovascular disease has attracted a great deal of attention. Even a small decline in renal function has been reported to be associated with increased mortality, length of stay, and cost in hospitalized patients. ${ }^{5}$

Thus, this study aimed to evaluate the in-hospital outcomes between patients of ACS with or without AKI. It helps to know better about the outcomes and its implication to reduce knowledge gap as well regular follow up patient before developing any major adverse effect along with chronic renal failure.

\section{Materials and Methods:}

This prospective comparative study was conducted in the Department of Cardiology, Bangabandhu Sheikh Mujib Medical University (BSMMU), Dhaka,Bangladesh, during the period of August 2017 to July 2018. A total of 70 eligible patients were included in this study of which 35 patients were included in group A (ACS with AKI) and 35 patients were included in group $\mathrm{B}$ (ACS without AKI) with following inclusion and exclusion criteria.

\section{Inclusion Criteria:}

- Patients diagnosed as ACS(STEMI/NSTEMI/UA) according to ACC/AHA guideline.

- Patients age $\geq 18$ years-old of both sex
- Hospitalization for $\geq 48 \mathrm{hrs}$.

- At least four sample of Serum Creatinine (S. Cr) measurements during hospitalization.

\section{Exclusion Criteria:}

- Patient refused taking part in study.

- Patients with history of any previous Myocardial Infarction (MI).

- Patients with history of PCI or CABG.

- Patients with any valvular heart disease, congenital heart disease or primary myocardial or pericardial disease.

- Patients with co-morbidities like CKD, COPD, ESRD, CLD, malignancy.

The study was performed according to the guideline of the Helsinki Declaration and was aprroved by the institutional Review Board(IRB).

AKI was diagnosed, on the basis of increased serum creatinine level $0.3 \mathrm{mg} / \mathrm{dL}$ from baseline within 48 hours after hospitalization. They were subjected to electrocardiography, blood test for serum creatinine (on admission, 12 hours, 48 hours and at the time of discharge), lipid profile, Blood sugar, 2-D echocardiography along with Serum Troponin, CK MB and electrolytes.

On admission serum creatinine was normal to all selected study population. After admission, all the patients in study group were observed and monitored for 48 hours and further two samples of blood for serum creatinine were taken on $12 \mathrm{hrs}$ and $48 \mathrm{hrs}$. All the blood reports were collected from patient's clinical record files. The patients whom, serum creatinine $0.3 \mathrm{mg} / \mathrm{dL}$ increased from baseline level (on admission) within $48 \mathrm{hrs}$ considered as cut off value to diagnose AKI. In this way, after $48 \mathrm{hrs}$ of admission, 35 patients who developed AKI were considered as group A and 35 patients who did not develop AKI were considered as group B. The guideline directed medical therapy was given to both groups and follow up was done. The transthoracic echocardiography was performed. The regional wall motion abnormality and left ventricular ejection fraction (LVEF) were measured. Both the groups were evaluated by day to day new change in history and clinical examination till hospitalization. In-hospital outcomes (heart failure, cardiogenic shock, arrhythmia, requirement of dialysis, duration of hospital stay and death) of ACS patients with AKI and without AKI were observed and recorded. The total duration of hospital stay of both the groups was recorded. The last sample of serum creatinine was done on discharge. 


\section{Statistical analysis}

After complied data collection from all patients, statistical analysis was performed using the statistical package for social sciences (SPSS) program, version 23 for windows. Continuous parameters were expressed as mean $\pm \mathrm{SD}$ and categorical parameters as frequency and percentage. Comparisons between groups (continuous parameters) were done by Unpaired student's t test. Categorical parameters were compared by Chi-Square test. Multivariate logistic regression analysis was performed to identify In-hospital mortality risk among patients with AKI. The significance of the results as determined in $95.0 \%$ confidence interval and a value of $p<0.05$ was maintained.

\section{Results:}

A total of 70 patients were included in this study of which 35 patients were included in group A (ACS with AKI) and 35 patients were included in group B (ACS without AKI)(Table-I).The mean serum creatinine level of group A was $1.92 \pm 0.9$ and group B was $1.04 \pm 0.15$ (Table-II). Patients were distributed as $48.5 \%$ were in stage I, $17.3 \%$ were in stage II and $34.2 \%$ werein stage III in AKI patients within 48 hours of hospitalization (Table-III).

\section{Table-I}

Comparison of study patients by age $(N=70)$

\begin{tabular}{lccc}
\hline Age in years & $\begin{array}{c}\text { Group A } \\
\mathrm{n}=35(\%)\end{array}$ & $\begin{array}{c}\text { Group B } \\
\mathrm{n}=35(\%)\end{array}$ & P value \\
\hline $30-40$ & $1(2.9)$ & $4(11.4)$ & \\
$41-50$ & $6(17.1)$ & $7(20.0)$ & \\
$51-60$ & $14(40.0)$ & $12(34.3)$ & \\
$\geq 60$ & $14(40.0)$ & $12(34.2)$ & \\
Mean \pm SD & $58.0 \pm 8.5$ & $55.6 \pm 12.3$ & 0.337 \\
Range & $34-76$ & $33-95$ & \\
\hline
\end{tabular}

Data were analyzed using student's $t$-test and the level of significance was 0.05 .

Table II

Comparison of study patients by Serum Creatinine $(N=70)$

\begin{tabular}{lcc}
\hline & $\begin{array}{c}\text { Group A } \\
(\mathrm{n}=35) \\
(\mathrm{Mean} \pm \mathrm{SD})\end{array}$ & $\begin{array}{c}\text { Group B } \\
(\mathrm{n}=35) \\
(\text { Mean } \pm \mathrm{SD})\end{array}$ \\
\hline Serum Creatinine $(\mathrm{mg} / \mathrm{dL})$ & $1.92 \pm 0.90$ & $1.04 \pm 0.15$ \\
\hline $\begin{array}{l}\text { Data were analyzed using student's } t \text {-test and the level of significance } \\
\text { was } 0.05 .\end{array}$
\end{tabular}

Table-III

Distribution of AKI stages $(N=35)$

\begin{tabular}{lcc}
\hline AKI stage & Frequency & Percentage (\%) \\
\hline Stage I & 17 & 48.5 \\
Stage II & 6 & 17.3 \\
Stage III & 12 & 34.2 \\
\hline
\end{tabular}

The first sample was taken on admission (Group $A=0.9806$ and Group $B=0.966$ ), after 12 hours of admission (Group $\mathrm{A}=1.84$ and Group $\mathrm{B}=1.0283$ ), after 48 hours of admission (Group $\mathrm{A}=2.9597$ and Group $\mathrm{B}=1.139$ ) and before discharge (Group $A=3.3729$ and Group B=0.9894) (Figure-1)

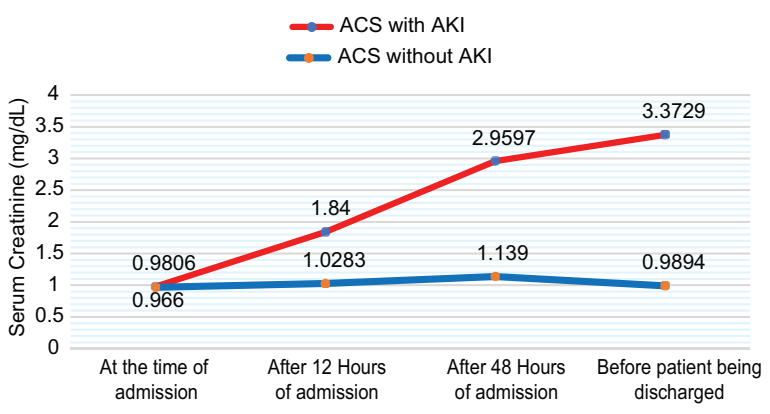

Fig.-1: Time graph showing comparison of Serum Creatinine levels in both groups.

Comparison of study patients by risk factors of coronary heart disease (CAD). All the risk factors except smoking were more or equally distributed in both the groups. The predominant risk factor was hypertension ( $77.1 \%$ vs $74.2 \%)$ in both groups followed by diabetes mellitus $(62.8 \%$ vs $48.5 \%)$ and dyslipidemia (45.7\% vs $42.8 \%$ ) respectively in both the groups. Family history of IHD was equally present in both the groups. The difference in these risk factor along with family history of IHD were not statistically significant. The smoking was predominant $27(77 \%)$ in group A than 17(48.5\%) group B which was statistically significant between the groups.(Table-IV)

Comparison of study patients by haemodynamics. It was observed that the mean systolic blood pressure and diastolic blood pressure was lower in group A than group B (106.4 \pm 20.5 vs $131.7 \pm 25.9,69.1 \pm 12.4$ vs $83.1 \pm 15.4$ respectively $=0.001$ ) which was statistically significant. The mean heart rate was higher in group A than group B ( $92.2 \pm 24.3$ vs $87.2 \pm 15.3$ respectively; $p=0.314$ ). The difference was not statistically significant (Table-V). 
The base line investigations of the study population. It was observed that the ECG changes of ST elevation were more common in Group A than Group B (88.6\% vs $57.1 \%$ respectively) whereas ST depression were more common in Group B than Group A (42.9\% vs $11.4 \%$ respectively. It was statistically significant between groups ( $p=0.001)$. The mean LVEF were significantly lower in the Group A than in the Group B $(41.6 \pm 7.4$ Vs $50.1 \pm 8.5$ respectively $p=0.001$ ) these were statistically significant in between the groups. The mean random blood sugar (RBS) was higher than in group A than group $\mathrm{B}(12.0 \pm 5.4 \mathrm{Vs} 9.9 \pm 4.2)$ which was not statistically significant (Table- VI)

The comparison study patients by in-hospital adverse outcomes. It was observed that heart failure was more common in group A than in Group B (74.3\% Vs 34.2\%; $\mathrm{p}=0.001$ respectively). This was statistically highly significant in between both groups. It was observed that cardiogenic shock was more common in group A than in Group B (51.4\% Vs 14.2\% p=0.001 respectively). This was statistically highly significant in between both groups. Arrhythmia was more common in group A than in Group B ( $100 \%$ Vs $0 \% ; p=0.001$ respectively). This was statistically highly significant in between both groups. It was observed that $7(20 \%)$ patients of group A required urgent dialysis than in the group B. This was statistically highly significant

Table-IV

Comparison of study patients by risk factors $(N=70)$

\begin{tabular}{cccc}
\hline & $\begin{array}{c}\text { Group A } \\
\mathrm{n}=35\end{array}$ & $\begin{array}{c}\text { Group B } \\
\mathrm{n}=35\end{array}$ & P value \\
\hline $\begin{array}{cccc}\text { Smoking } \\
\text { Yes }\end{array}$ & $\begin{array}{c} \\
27(77.1)\end{array}$ & $17(48.5)$ & 0.013 \\
No & $8(22.9)$ & $18(51.5)$ & \\
Dyslipidemia & & & \\
$\quad$ Yes & $16(45.7)$ & $15(42.8)$ & $0.810^{\text {ns }}$ \\
No & $19(54.3)$ & $20(57.2)$ &
\end{tabular}

Family history of IHD

$\begin{array}{cccc}\text { Yes } & 7(20.0) & 7(20) & 1.000^{\text {ns }} \\ \text { No } & 28(80.0) & 28(80.0) & \end{array}$

Hypertension

Yes $\quad 27(77.1) \quad 26(74.2) \quad 0.780^{\text {ns }}$

No $\quad 8(22.9) \quad 9(25.8)$

Diabetes Mellitus

$\begin{array}{llll}\text { Yes } & 22(62.8) & 17(48.5) & 0.229^{\text {ns }} \\ \text { No } & 13(37.2) & 18(51.5) & \end{array}$

Data were analyzed using Chi-square $\left(\chi^{2}\right)$ test and the level of significance was 0.05 . in between the groups. It was also observed that 2(5.7\%) patients dead in group A than in group B (Table-VII)

The comparison of hospital stay between the groups. The mean duration of hospital stay was significantly higher in the Group A than in the Group B $(9.4 \pm 2.3$ vs $7.2 \pm 0.6$; $\mathrm{p}=0.001$ ) days. This was statistically highly significant (Table-VIII)

Multiple logistic regression analysis of odds ratio for characteristics of the subjects likely affect the outcome of patient between two groups. It revealed that smoking, heart failure, cardiogenic shock, hospital stay were found to be the independently significant predictors outcome of the patients with AKI Odds ratio being $3.57(\mathrm{P}=0.001), 5.53$ $(\mathrm{P}=.001), 4.353(\mathrm{P}=0.02)$ and $6.92(\mathrm{P}=.001)$ respectively. But age $(>60), \mathrm{HTN}$ and DM were found no significant predictor outcome of the patient with AKI Odds ratio being 0.78 $(\mathrm{P}=.621), 0.83(\mathrm{P}=.78)$ and $0.43(\mathrm{P}=.257)$. (Table-IX)

Table-V

Comparison of study patients

by Haemodynamics $(N=70)$

\begin{tabular}{lccc}
\hline & $\begin{array}{c}\text { (Group A) } \\
(\mathrm{n}=35)\end{array}$ & $\begin{array}{c}\text { (Group B) } \\
(\mathrm{n}=35)\end{array}$ & P value \\
\hline $\begin{array}{l}\text { Systolic BP (mmHg) } \\
\text { (On Admission) }\end{array}$ & $106.4 \pm 20.5$ & $131.7 \pm 25.9$ & 0.001 \\
{$[$ Mean \pm SD $]$} & & \\
$\begin{array}{l}\text { Diastolic BP (mmHg) } \\
\text { (On Admission) }\end{array}$ & & & \\
[Mean \pm SD] & & & \\
\# Data were analyzed using student's $t$-test and the level of \\
significance was 0.05. \\
* Data were analyzed using Chi-square ( test \& Fisher's Exact Test. \\
The level of significance was 0.05.
\end{tabular}

Table-VI

Comparison of study patients by investigations $(\mathrm{N}=70)$

\begin{tabular}{lccc}
\hline & $\begin{array}{c}\text { (Group A) } \\
(\mathrm{n}=35)\end{array}$ & $\begin{array}{c}(\text { Group B }) \\
(\mathrm{n}=35)\end{array}$ & P value \\
\hline ECG $^{*}$ & & & \\
$\quad$ ST Elevation & $31(88.6)$ & $20(57.1)$ & 0.012 \\
$\quad$ ST Depression & $4(11.4)$ & $13(42.9)$ & \\
$\mathrm{LVEF}^{\#}[\mathrm{Mean} \pm \mathrm{SD}]$ & $41.6 \pm 7.4$ & $50.1 \pm 8.5$ & 0.001 \\
$\mathrm{RBS}(\mathrm{mg} / \mathrm{dL})$ & $12.0 \pm 5.4$ & $9.9 \pm 4.2$ & $0.076^{\mathrm{ns}}$ \\
{$[\mathrm{Mean} \pm \mathrm{SD}]$} & & & \\
\hline \# Data were analyzed using student's $t$-test and the level of \\
significance was 0.05. \\
* Data were analyzed using Chi-square ( test and the level of \\
significance was 0.05.
\end{tabular}


Table-VII

Comparison of study patients by in-hospital adverse outcomes ( $N=70)$

\begin{tabular}{|c|c|c|c|}
\hline Group A(n=35) & Group B $(\mathrm{n}=35)$ & P value & \\
\hline Heart Failure & & & 0.001 \\
\hline Yes & $26(74.3)$ & $12(34.2)$ & \\
\hline No & $9(25.7)$ & $23(65.8)$ & \\
\hline \multicolumn{4}{|l|}{ Cardiogenic Shock } \\
\hline Yes & $18(51.4)$ & $5(14.2)$ & 0.001 \\
\hline No & $17(48.6)$ & $30(85.8)$ & \\
\hline \multicolumn{4}{|l|}{ Arrhythmia } \\
\hline Yes & $35(100)$ & $26(74.2)$ & 0.001 \\
\hline No & 0 & $9(25.8)$ & \\
\hline \multicolumn{4}{|c|}{ Requirement of dialysis } \\
\hline Required & $7(20)$ & $0(00)$ & 0.005 \\
\hline Not required & $28(80)$ & $35(100)$ & \\
\hline \multicolumn{4}{|l|}{ Death } \\
\hline Yes & $2(5.7)$ & 0 & 0.493 \\
\hline No & $33(94.3)$ & $35(100)$ & \\
\hline Heart Failure & & & 0.001 \\
\hline Yes & $26(74.3)$ & $12(34.2)$ & \\
\hline No & $9(25.7)$ & $23(65.8)$ & \\
\hline \multicolumn{4}{|l|}{ Cardiogenic Shock } \\
\hline Yes & $18(51.4)$ & $5(14.2)$ & 0.001 \\
\hline No & $17(48.6)$ & $30(85.8)$ & \\
\hline \multicolumn{4}{|l|}{ Arrhythmia } \\
\hline Yes & $35(100)$ & $26(74.2)$ & 0.001 \\
\hline No & 0 & $9(25.8)$ & \\
\hline \multicolumn{4}{|c|}{ Requirement of dialysis } \\
\hline Required & $7(20)$ & $0(00)$ & 0.005 \\
\hline Not required & $28(80)$ & $35(100)$ & \\
\hline \multicolumn{4}{|l|}{ Death } \\
\hline Yes & $2(5.7)$ & 0 & 0.493 \\
\hline No & $33(94.3)$ & $35(100)$ & \\
\hline
\end{tabular}

Data were analyzed using Chi-square ( test and the level of significance was 0.05 .

Data were analyzed using Fisher's Exact Test and the level of significance was 0.05.

Table VIII

Comparison of study patients by in-hospital stay $(N=70)$ between the groups.

\begin{tabular}{lccc}
\hline & Group A $(\mathrm{n}=35)$ & Group B $(\mathrm{n}=35)$ & P value \\
\hline Duration of hospital stay (Days) & $9.4 \pm 2.3$ & $7.2 \pm 0.6$ & 0.001 \\
\hline
\end{tabular}

Data were analyzed using student's $t$-test and the level of significance was 0.05 . 
Table-IX

Multiple Logistic regression analysis of determinants including outcome of patients between two groups $(n=70)$

\begin{tabular}{lcccccc}
\hline & Beta & S.E & P value & OR & \multicolumn{2}{c}{$95 \%$ CI } \\
\cline { 5 - 7 } & & & & & Lower & Upper \\
\hline Age $(>60)$ & 0.24 & 0.96 & 0.621 & 0.783 & 0.296 & 2.068 \\
HTN & 0.15 & 0.58 & 0.781 & 0.834 & 0.391 & 1.247 \\
DM & 0.58 & 0.48 & 0.257 & 0.431 & 0.690 & 2.365 \\
Smoking & 1.27 & 0.52 & 0.015 & 3.574 & 1.275 & 10.014 \\
Heart Failure & 1.71 & 0.526 & 0.001 & 5.537 & 1.977 & 5.516 \\
Cardiogenic Shock & 1.84 & 0.590 & 0.002 & 4.353 & 2.000 & 8.179 \\
Arrhythmia & 0.20 & 0.127 & 0.103 & 1.230 & 0.959 & 1.579 \\
Hospital stays (>7 days) & 3.39 & 0.930 & 0.001 & 6.922 & 0.039 & 1.342 \\
\hline
\end{tabular}

\section{Discussion:}

This prospective comparative cross-sectional study was carried out to determine in-hospital outcomes (heart failure, cardiogenic shock, arrhythmia, need for requirement of dialysis, total days of hospital stay and death) between patients of ACS with or without AKI.

This study shows the mean age were $58.0 \pm 8.5$ years in group A and $55.6 \pm 12.3$ years in group B. Majority ( $80 \%)$ were $>50$ years age in group $A$ and $(68.5 \%)$ in group $B$. The patients with AKI were older, more likely to have comorbidities. The age distribution of this study was comparatively lower than the study done by Marenzi et al. (2010). ${ }^{4}$ The mean age was $69 \pm 12$ years in group $A$ and $63 \pm 10$ years in group B. Similarly, the mean age of groups was higher in Fox et al. (2012). ${ }^{6}$ It was $68.3 \pm 12.37$ years in group A and $61.8 \pm 12.5$ years in group B. Our study groups had lower mean age groups giving impression of early $\mathrm{CAD}$ in this region.

Regarding gender distribution in this study population was male predominance in both the groups. $30(85.7 \%)$ patients were male in Group A and 26 (74.2\%) group B. 5 (14.3\%) female patients were in Group A and 9 (25.8\%) in Group B. Therefore, the findings of the study are in well agreement with the findings of the other research works (Marenzi et al. 2016). ${ }^{7}$ Shacham et al. $2014^{8}$ also observed the similar male gender predominance in both the study groups ( $81 \%$ vs $66 \%$ respectively). So, study supports the evidence of late CHD in female occurring after menopause and less in number.

In this study shows the mean serum creatinine level of group A was $1.92 \pm 0.9$ and group B was $1.04 \pm 0.15$. It observed that serum creatine level was higher in group A than group B. Therefore, the findings of the study are in well agreement with the findings of the other research works (Fox et al. 2012). ${ }^{6}$ In group A patients had acute massive myocardial injury which resulted in more renal impairment than group B.

This study found risk factors except smoking were significantly higher in group A than group B which was $77 \%$ vs $48.5 \%$ respectively. The predominant risk factor was hypertension were more in group A than group B ( $77.1 \%$ vs $74.2 \%$ respectively). Diabetes mellitus was more in group A than group B which was $62.8 \%$ vs $48.5 \%$ respectively and dyslipidemia was also more in group $\mathrm{A}$ than group B which was $45.7 \%$ vs $42.8 \%$ respectively. But Family history of IHD was equally present in both the groups. Therefore, the findings of the study are in well agreement with the findings of the other research workers (Marenzi et al. 2010 and Fox et al. 2000). ${ }^{4,6}$ Another study Moriyama et al. (2017) $)^{9}$ reported smoking, hypertension, diabetes mellitus, dyslipidemias were higher in AKI than without AKI.

Subject of systolic blood pressure in this study shows the mean, on admission, systolic blood pressure and diastolic blood pressure were lower in group A than group B $(106.4 \pm 20.5$ vs $131.7 \pm 25.9,69.1 \pm 12.4$ vs $83.1 \pm 15.4$ respectively; $p=0.001$ ) which was statistically significant. The mean heart rate was higher in group A than group B (92.2 \pm 24.3 Vs $87.2 \pm 15.3$ respectively; $p=0.001)$. The difference was not statistically significant. Therefore, the findings of the study are in well agreement with the findings of the other research works (Hwang et al. 2011). ${ }^{10} \mathrm{Hence}$, it points toward poor haemodynamics parameters in patients with ACS having renal impairment during on admission.

In this study shows the ECG Changes of ST elevation were more in patients with AKI (Group A) than patients 
with without AKI (Group B) which was $88.6 \%$ vs 57.1\% respectively. But ST depression were more in patients without AKI (Group B) than patients with AKI (Group A) which was $42.9 \%$ vs $11.4 \%$ respectively. It was statistically significant between groups ( $p=0.012$ ). The least common was unstable angina (UA). Similar studies found ECG changes of ST elevation were more in patients with AKI (Marenzi et al. 2012; Bruetto et al. 2012). ${ }^{11,12}$ Also, in previous study (Moriyama et al. 2017) ${ }^{13}$ found $88 \%$ STEMI in with AKI and $82 \%$ STEMI in without AKI. So, STEMI patients were in majority and had worse renal impairment than with NSTEMI.

This study shows the mean LVEF was significantly lower in the Group A than in the Group B $(41.6 \pm 7.4$ vs $50.1 \pm 8.5$ respectively $p=0.001)$ these were statistically significant in between the groups. The mean, on admission, random blood sugar (RBS) was higher than in group A than group B (12.0 \pm 5.4 vs 9.9 \pm 4.2$)$ which was not statistically significant. These finding were consistent with other studies (Marenzi et al. 2010; Marenzi et al. 2013; Parikh et al. 2008). ${ }^{4,11,14}$

The present study shows that heart failure was more common in group A than in Group B (74.3\% vs 34.2\%; $p=0.001$ respectively). This was statistically highly significant in between two groups. Parikh et al. $2008^{14}$ study found almost similar results (75\% vs $42.7 \%$ respectively). Another study (Marenzi et al. 2013) ${ }^{11}$ noticed that patients with AKI had $61 \%$ and without AKI had $8 \%$ of in-hospital heart failure.

In this study, Cardiogenic shock was more common in group A than in Group B (51.4\% vs $14.2 \% p=0.001$ respectively). This was statistically highly significant in between two groups. Therefore, the findings of the study are in well agreement with the findings of the other research works (Marenzi et al. 2010 and Hwang et al. 2011). 4,10

This study shows the arrhythmia was significantly higher in group A than in Group B (100\% vs $74.2 \% ; p=0.001$ respectively). Sinus tachycardia, AV blocks and Ventricular tachycardia (VT)/ ventricular fibrilation (VF) were higher in group A than group B. It was observed that 7(20\%) of patients required dialysis and $2(5.7 \%)$ death in group A. These finding were consistent with other studies (Parikh et al. 2008; Marenzi et al. 2013; Marenzi et al. 2010). ${ }^{4,11,14}$

In this study found mean duration of hospital stays was significantly higher in the Group A than in the Group B (9.4 \pm 2.3 vs $7.2 \pm 0.6 ; p=0.001)$. This was statistically highly significant between two groups. Marenzi et al. 2010 observed that longer hospital stays of patients with AKI.
The recovery time for patients with AKI was longer due to more complicated course of disease.

Multiple Logistic regression analysis revealed that Smoking, Heart failure, Cardiogenic shock, Hospital stay were found to be the independently significant predictors outcome of the patients with AKI Odds ratio being 3.57 $(\mathrm{P}=0.001), 5.53(\mathrm{P}=.001), 4.353(\mathrm{P}=0.02)$ and $6.92(\mathrm{P}=0.001)$ respectively. But age $(>60), \mathrm{HTN}$ and DM were found no significant predictor outcome of the patient with AKI Odds ratio being $0.78(\mathrm{P}=0.621), 0.83(\mathrm{P}=0.78)$ and $0.43(\mathrm{P}=0.257)$. Therefore, the findings of the study are in well agreement with the findings of the other research works (Hwang et al. 2011 and Marenzi et al. 2010). ${ }^{4,14}$

\section{Limitations of the Study:}

- This study recorded only in-hospital (short term) outcomes of heart failure, cardiogenic shock, arrhythmia, dialysis requirement and death. So, complication in the long run could not be determined.

- The study was conducted in a single tertiary level hospital which may not represent the general population.

- The patients with ACS with or without AKI were not included due to different exclusion criteria.

\section{Conclusion:}

This study shows that presence of AKI in patients with ACS is associated with adverse in- hospital outcomes in terms of heart failure, cardiogenic shock, arrhythmia and death. It also shows longer duration of hospital stay. So, the presence of AKI in patients with ACS should alert physicians to an increase risk of morbidity and mortality. These findings give emphasis on our consciousness in management and outcomes for acute coronary syndrome patients with acute kidney injury in CCU.

\section{Recommendation}

- ACS patients with AKI should be classified, monitored and interpreted with the help of easily available serum creatinine level meticulously during hospitalization.

- A routine serum creatinine should be done within 48 hours of hospitalization.

- Follow up post MI with renal impairment should be done with serum creatinine after hospital discharge.

\section{References:}

1. Cannon, C, Brindis, R, Chaitman, B, Cohen, D, Cross, J, Drozda, J. et al. ACC/AHA Key Data Elements and Definitions for Measuring the Clinical Management and Outcomes of Patients with Acute Coronary Syndromes and Coronary Artery 
Disease: A Report of the American College of Cardiology Foundation/American Heart Association Task Force on Clinical Data Standards, Circulation 2013;127(9): 1052-89.

2. Hoste, E.A, Kellum, J.A, Selby, N.M, Zarbock, A, Palevsky, P.M, Bagshaw, S.M. et al. Global epidemiology and outcomes of acute kidney injury, Nature Reviews Nephrology 2018; 1.

3. Ronco, C, McCullough, P, Anker, S, Anand, I, Aspromonte, N, Bagshaw, S. et al. Cardio-renal syndromes: report from the consensus conference of the Acute Dialysis Quality Initiative, European Heart Journal 2009; 31(6): 703-11

4. Marenzi, G, Assanelli, E, Campodonico, J, De Metrio, M, Lauri, G, Marana, I. et al. Acute kidney injury in ST-segment elevation acute myocardial infarction complicated by cardiogenic shock at admission, Critical care medicine 2010; 38(2): 438-44.

5. Anzai, A, Anzai, T, Naito, K, Kaneko, H, Mano, Y, Jo, Y, Nagatomo, Y, Prognostic significance of acute kidney injury after reperfused ST-elevation myocardial infarction: synergistic acceleration of renal dysfunction and left ventricular remodeling, Journal of cardiac failure 2010; 16(5): 381-89.

6. Fox, C.S, Muntner, P, Chen, A.Y, Alexander, K.P, Roe, M.T. and Wiviott, S.D, Short-term outcomes of acute myocardial infarction in patients with acute kidney injury: a report from the national cardiovascular data registry, Circulation 2012; 125(3): 497-504.

7. Marenzi, G, Cosentino, N, Moltrasio, M, Rubino, M, Crimi, G, Buratti, S. et al. Acute kidney injury definition and in hospital mortality in patients undergoing primary percutaneous coronary intervention for ST segment elevation myocardial infarction, Journal of the American Heart Association 2016; 5(7): e035-22.

8. Shacham, Y, Leshem-Rubinow, E, Steinvil, A, Assa, E.B, Keren, G, Roth, A. et al. Renal impairment according to acute kidney injury network criteria among ST elevation myocardial infarction patients undergoing primary percutaneous intervention: a retrospective observational study, Clinical Research in Cardiology 2014;103(7): 525-532.

9. Moriyama, N, Ishihara, M, Noguchi, T, Nakanishi, M, Arakawa, T, Asaumi, Y. et al. Early development of acute kidney injury is an independent predictor of in-hospital mortality in patients with acute myocardial infarction, Journal of cardiology 2107; 69(1): 79-83.

10. Hwang, S.H, Jeong, M.H, Ahmed, K, Kim, M.C, Cho, K.H, Lee, M.G. et al. Different clinical outcomes of acute kidney injury according to acute kidney injury network criteria in patients between ST elevation and non-ST elevation myocardial infarction, International journal of cardiology 2011; 50(1): 99.

11. Marenzi, G., Cabiati, A., Bertoli, S., Assanelli, E., Marana, I., De Metrio, M, et al. Incidence and Relevance of Acute Kidney Injury in Patients Hospitalized with Acute Coronary Syndromes', The American Journal of Cardiology 2013; 111(6): 816-22

12. Bruetto, R.G, Rodrigues, F.B, Torres, U.S, Otaviano, A.P, Zanetta, D.M. and Burdmann, E.A. Renal function at hospital admission and mortality due to acute kidney injury after myocardial infarction, PLoS One 2012; 74: e354-96.

13. Moriyama, N, Ishihara, M, Noguchi, T, Nakanishi, M, Arakawa, T, Asaumi, Y. et al. Early development of acute kidney injury is an independent predictor of in-hospital mortality in patients with acute myocardial infarction, Journal of cardiology 2107; 69(1): 79-83.

14. Parikh, C, Coca, S, Wang, Y, Masoudi, F. and Krumholz, H. Long-term Prognosis of Acute Kidney Injury After Acute Myocardial Infarction, Archives of Internal Medicine 2008; 168(9): 987. 